\title{
Erratum to: Spectrofluorimetric Assessment of Doxycycline Hydrochloride in Pharmaceutical Tablets and Serum Sample Based on the Enhancement of the Luminescence Intensity of the Optical Sensor $\mathrm{Sm}^{3+}$ Ion
}

\author{
M. S. Attia • W. H. Mahmoud • M. N. Ramsis • \\ L. H. Khalil • A. M. Othman • S. G. Hashem • \\ M. S. Mostafa
}

Published online: 3 August 2011

(C) Springer Science+Business Media, LLC 2011

Erratum to: J Fluoresc (2011) 21:1739-1748

DOI 10.1007/s10895-011-0869-4

The original version of this article unfortunately contained errors in the text. The corrections are as follows:

- In page 6, right paragraph line 13

"of melamine. Bias $\{$ bias\% $\%=[$ Concentration found - known" must be changed to "of DC. Bias $\{$ bias $\%=[($ Concentration found - known"

- In Table 5

The value of the detection limit of the present work in column 3 in last row $6.5 \times 10^{-9}$ must be changed to $6.5 \times 10^{-10}$

The online version of the original article can be found at http://dx.doi. org/10.1007/s10895-011-0869-4.

M. S. Attia $(\bowtie) \cdot$ M. N. Ramsis $\cdot$ L. H. Khalil · S. G. Hashem •

M. S. Mostafa

Department of Chemistry, Faculty of Science,

Ain Shams University,

Cairo, Egypt

e-mail: Mohamed_sam@yahoo.com

W. H. Mahmoud

Chemistry Department, Faculty of Applied Science,

Taibah University,

Al-Madinah, Al-Munawarah, Kingdom of Saudi Arabia

A. M. Othman

Department of environmental biotechnology,

Genetic Engineering and Biotechnology Research Institute (GEBRI),

Minofiea University,

Sadat City, Egypt 